Avian Loren C. Carlos, MD, MBA'

January E. Gelera, MD ${ }^{1,2}$

'Department of Otorhinolaryngology Head and Neck Surgery

'Amang' Rodriguez Memorial Medical Center

2Department of Otorhinolaryngology

Head and Neck Surgery

University of Santo Tomas
Correspondence: Dr. January E. Gelera Department of Otorhinolaryngology

Head and Neck Surgery

'Amang' Rodriguez Memorial Medical Center

Sumulong Hi-way, Sto. Niño, Marikina City 1800

Philippines

Phone: (632) 941-5854

Email: vignettejan@gmail.com

The authors declare that this represents original material, that the manuscript has been read and approved by all the authors, that the requirements for authorship have been met by each author, and that each author believes that the manuscript represents honest work.

Disclosures: The authors signed disclosures that there are no financial or other (including personal) relationships, intellectual passion, political or religious beliefs, and institutional affiliations that might lead to a conflict of interest.

Presented at the 10th International Symposium on Recent Advances in Rhinosinusitis and Nasal Polyps, and 61st Annual Convention of the Philippine Society of Otolaryngology Head and Neck Surgery. "Cesar Villafuerte Sr. Research Contest". November 30, 2017. Manila Hotel, Manila.

Presented at the 10th International Academic Conference in Otology, Rhinology, and Laryngology (ORLIAC). March 2, 2018. Fairmont Hotel, Makati, Metro Manila.

\section{$\Theta(\Theta \Theta$}

\title{
Prevalence of Supraorbital Ethmoid Air Cells among Filipinos
}

\begin{abstract}
Objective: This study aims to determine the prevalence of supraorbital ethmoidal cells (SOEC) among Filipinos in a single tertiary government institution.
\end{abstract}

\section{Methods:}

$\begin{array}{ll}\text { Design: } & \text { Retrospective review of CT scan images } \\ \text { Setting: } & \text { Single Tertiary Institution } \\ \text { Patients: } & 123 \text { patients aged 13-years-old and above }\end{array}$

Results: A total of 474 CT scans (60 PNS and 414 Craniofacial) performed during the study period were considered with 55 excluded for age $<13$ and 296 excluded for craniofacial fractures. None had congenital craniofacial deformities. Eighty-five (85) of 123 CT scans (69.11\%) or 147 of 246 sides $(59.76 \%)$ demonstrated supraorbital ethmoidal cells. There were 62 (72.94\%) males and 23 (27.06\%) females, ages ranging from 13 to 83 (mean age between male and female was 39.53 and 43.57). The scans showed $62(50.41 \%)$ patients with bilateral and $23(18.70 \%)$ with unilateral SOEC. Twenty-two (25.9\%) patients were identified with chronic rhinosinusitis and two of whom were considered to have maxillary sinus mass. Two out of 5 patients with SOEC presented with aplastic/hypoplastic frontal sinus.

Conclusion: Our study suggests that Filipinos may have a higher prevalence rate of SOEC than their Chinese, Japanese and Korean counterparts and bilateral SOEC are more predominant than unilateral SOEC.

Keywords: supraorbital ethmoid cell, anterior ethmoid artery, paranasal CT scan, craniofacial CT scan, frontal sinus surgery

Completing a functional endoscopic sinus surgery for frontal sinus diseases entails opening and clearing of the frontal recess. Computed Tomographic (CT) scans are used as a roadmap to guide surgeons in preventing such complications as bleeding, orbital injuries and CSF leaks. In particular, anterior ethmoid artery (AEA) bleeds are serious, and difficulty in identifying the AEA predisposes to intraoperative complications. With the advent of technology, an endoscopic approach provides an effective means to approximate the location of the AEA. Several studies have shown that with identification of supraorbital ethmoidal cells (SOEC)-- the "pneumatization of the orbital plate of the frontal bone" located posterolateral to the frontal sinus ${ }^{1}$-- AEA location can be predicted..$^{1-5}$ 
The prevalence of SOEC in Caucasians is high, involving more than $60 \%$ of the population according to 3 studies..$^{5-7}$ Ethnic variations in incidence have been reported ranging from $2.4 \%$ in Koreans, $5.4 \%$ in Chinese to $36 \%$ in blacks and $69 \%$ in Caucasians. ${ }^{8}$ Ethnic variations may be a determining factor for the course of the AEA and comparative studies have stated that Caucasians have a tendency for supraorbital ethmoidal cells while Asians have a tendency for suprabullar cells.,9 We can neither confirm nor deny these findings, because to the best of our knowledge, a search of MEDLINE (PubMed), HERDIN, EMBASE, and Google Scholar, yielded no published studies on the prevalence of supraorbital ethmoidal cells in Filipinos.

Hence, this study aims to determine the prevalence of supraorbital ethmoidal cells (SOEC) among Filipinos in a single tertiary government institution.

\section{Study Design}

\section{METHODS}

With approval of the 'Amang' Rodriguez Memorial Medical Center Institutional Review Board (ERB Protocol Number: R- 2017-08-00), this was a retrospective review of Paranasal Sinus (PNS) CT scans and Craniofacial CT scans done at a single tertiary government hospital from October 2016 to August 2017.

\section{Subjects}

All PNS and Craniofacial CT scans performed in 'Amang' Rodriguez Memorial Medical Center for various indications during the study period were retrieved chronologically and reviewed by both authors at the Radiology Department workstation. Demographic data included were: age, gender, presence and laterality of SOEC, presence of aplastic/ hypoplastic frontal sinuses, sinonasal diseases and tumors. Excluded were scans of patients below 13 years of age, patients with craniofacial fractures and patients with congenital craniofacial malformations.

\section{Computed Tomography Protocol and SOEC Identification}

All scans had been obtained using a Hitachi Eclos (Hitachi Medical Corp., Tokyo, Japan) using a fine-cut $(1.25-2.50 \mathrm{~mm})$ triplanar study in high-speed mode [collimation: $1.25 \times 8 \mathrm{~mm}$, scan time $21 \mathrm{~s}$, scan length: $250 \mathrm{~mm}$, rotation time: $1.0 \mathrm{~s}$, tube settings: $120 \mathrm{kV}, 150 \mathrm{mAs}$, Eff. Dose: $29.8 \mathrm{mGy}$ ]. Identification of the SOEC was consensually arrived at by both authors using Van Alyea's definition of $\mathrm{SOEC}^{3}$ tracing the border of this air cell from the anterior ethmoids superiorly towards the ethmoid roof and laterally towards the middle orbital wall. When in doubt, a board-certified radiologist was consulted to confirm SOEC.

\section{Data Analysis}

Data was recorded and tabulated using Microsoft ${ }^{\circ}$ Excel for Mac v. 16.16.3 (181015) (Microsoft Corp., Redmond, WA, USA) and simple descriptive statistics were applied.

\section{RESULTS}

A total of 474 CT scans (60 PNS and 414 Craniofacial) performed during the study period were considered with 55 excluded for age < 13 and 296 excluded for craniofacial fractures. None had congenital craniofacial deformities. Eighty-five (85) of 123 CT scans (69.11\%) or 147 of 246 sides $(59.76 \%)$ demonstrated SOEC. There were 62 (72.94\%) males and 23 (27.06\%) females, ages ranging from 13 to 83 (mean age between male and female was 39.53 and 43.57). The scans showed 62 (50.41\%) patients with bilateral and $23(18.70 \%)$ with unilateral SOEC. Figure 1 shows an example of a PNS CT scan with a unilateral SOEC on the left.
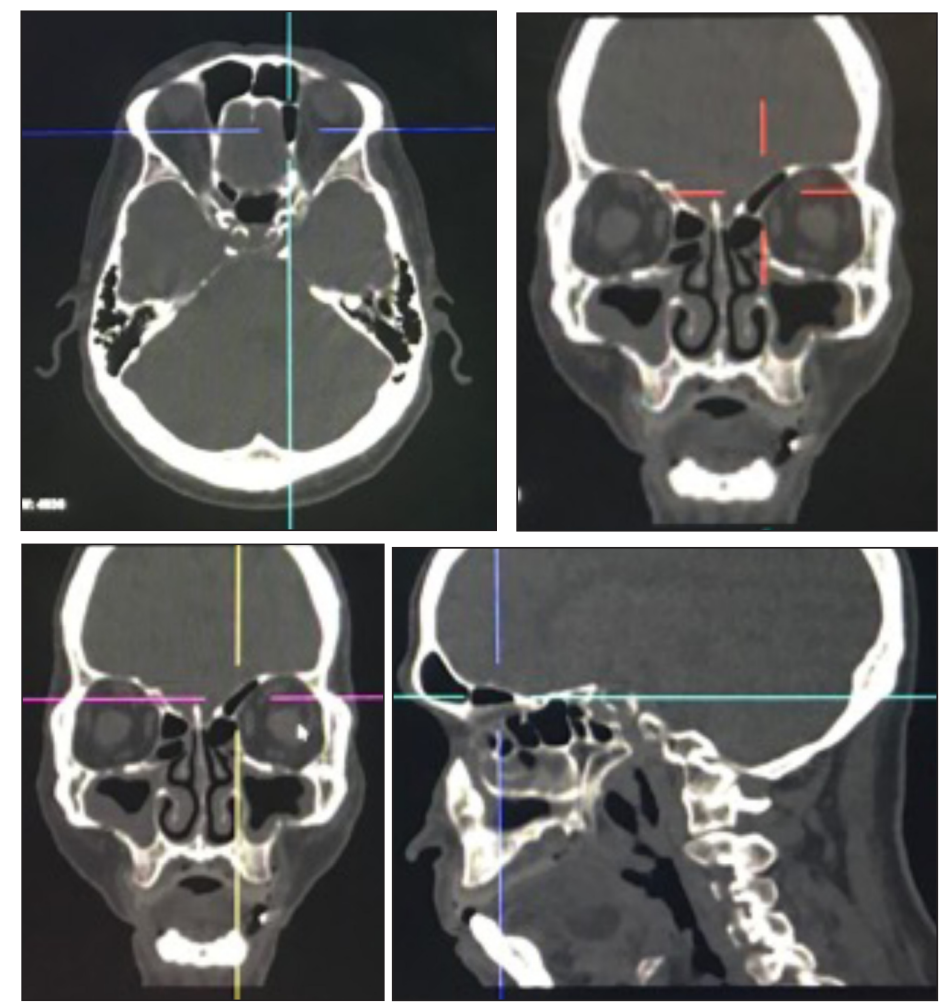

Figure 1. Representative PNS CT scan, bone window. (top right) Coronal view at the level of the orbital roof, with corresponding axial (top left) and sagittal (bottom right) views showing the presence of sinonasal disease in both maxillary sinuses and SOEC on the left frontal recess. Note the presence of the supraorbital ethmoid air cell extending posteriorly and superiorly over the left orbital roof within the ipsilateral frontal recess as seen on the sagittal and coronal views.

Twenty-two (25.9\%) patients were identified with chronic rhinosinusitis and two of whom were considered to have maxillary sinus mass. Also, 2 out of 5 patients with SOEC presented with aplastic/ hypoplastic frontal sinus. Table 1 summarizes the profiles of patients with SOEC and aplastic/hypoplastic frontal sinuses. 
ORIGINAL ARTICLES

Table 1. Profile of SOEC patients with aplastic/hypoplastic frontal sinus

\begin{tabular}{|c|c|c|c|c|} 
Patient & Age & Gender & $\begin{array}{c}\text { Aplastic/Hypoplastic } \\
\text { Sinus Laterality }\end{array}$ & $\begin{array}{c}\text { SOEC } \\
\text { Laterality }\end{array}$ \\
\hline 1 & 72 & F & B & - \\
\hline 2 & 60 & M & R & L \\
\hline 3 & 63 & F & R & - \\
\hline 4 & 24 & M & B & L \\
\hline 5 & 23 & F & B & - \\
\hline
\end{tabular}

\section{DISCUSSION}

The overall prevalence of supraorbital ethmoidal cells in our study was $69.1 \%$. This was $10 x$ more than that previously reported among Koreans $(2.4 \%){ }_{1}^{6}$ Chinese $(5.4 \%)^{5}$ and Japanese $(6 \%)^{7}$ but less than that reported among whites (64.6\%). ${ }^{6,10}$ Comparing the prevalence of SOEC with other races, Filipinos in our study have a more than $50 \%$ chance of having SOEC. Establishing the consistency of this air cell among Filipinos in general can make it a reliable landmark for identifying the AEA.

We compared our findings with previous studies on the prevalence of SOEC. A study by Bhatt et al. of 531 paranasal sinus CT scans showed a $56.3 \%$ prevalence of SOEC bilaterally and $4.7 \%$ unilaterally. ${ }^{4}$ Among Filipinos in our series, the presence of bilateral SOEC was higher than unilateral SOEC ( $62 \%$ vs $23 \%$, respectively). Compared to the general population, $50.4 \%$ would have bilateral SOEC and $18.7 \%$ would have unilateral SOEC. However, there are patients presenting with SOEC despite having a hypoplastic/aplastic frontal sinus. Comer et al. mentioned that septations of the frontal sinus have a higher correlation to the incidence of SOEC. The stated prevalence values in their study were said to be related to the craniofacial variations between the different ethnicities. It has been said that in Caucasians, the development of SOEC relates to the prominence of the glabella and superior orbital rim. It was also concluded that the skull base length and anteroposterior diameter of the skull was not significant in the development of SOEC. ${ }^{6}$ Frontal sinus septations were not measured in this study, however, we found that SOEC can be present despite having an aplastic or hypoplastic frontal sinus, as seen in Table 1.

Of the 85 patients with SOEC, 22 were radiographically diagnosed with sinonasal diseases. In terms of having pathology in the sinuses, a study of 70 PNS CT scans of patients who were to undergo FESS concluded there was "no significant difference in frontal sinus mucosal disease in presence or absence of frontal cells." ${ }^{16}$ Therefore, having sinonasal diseases would not change the presence or absence of SOEC in patients. However, having SOEC may predispose the patient to frontal sinusitis when the frontal sinus drainage pathway is obstructed. Kubota et al. reported that in patients with chronic rhinosinusitis, frontal bullar cells were more frequently seen. ${ }^{7}$ Jang et al. mentioned that there may be significant expansion of the SOEC due to pathology (laterally) but the AEA remain within its posterior border. $^{3}$ The 22 patients with sinonasal diseases in our study did not show any significant expansion of the SOEC radiographically making the location of the AEA still predictable.

Our study has several limitations. First, our study has design issues. Thus, despite the data obtained in our study, no correlations or associations were explored among variables. Further studies should be undertaken to establish such relationships. Second, our study has ascertainment and selection bias. Our sample of PNS CT scans consisted entirely of patients with indications for these scans and may not represent the larger population to which our results are meant to apply. Future studies can pay more attention to sample size, sampling methods and criteria for inclusion and exclusion. Third, our study also has observer bias. Assessment of SOEC was consensually performed by unblinded authors who were both ENT clinicians although a boardcertified radiologist was consulted for equivocal images. Independent evaluations by blinded board-certified radiologists may be performed in future studies. Despite these limitations, our study may be a stepping stone toward providing data for a meta-analysis among ASEAN countries provided that other ASEAN countries like Thailand, Malaysia, Indonesia conduct their own prevalence studies.

In conclusion, our study suggests that Filipinos may have a higher prevalence rate of SOEC compared to their Chinese, Japanese and Korean counterparts. Bilateral SOEC are more predominant than unilateral SOEC.

\section{ACKNOWLEDGEMENTS}

We would like to thank the ARMMC Department of Radiology for allowing us the use of their workstation.To Sumitanand Mishra, MBBS, PGDS, MD Radiology, April Camille G. Morillo, RN, MD and Rainier A. Agustines, MD for providing their technical knowledge and assistance in confirming the presence of SOEC in some of the scans. To Lourdes A. Tan, MD, DPBR for her technical knowledge and insights.

\section{REFERENCES}

1. Simmen D, Rghavan U, Briner HR, Schuknecht B, Groscurth $P$, Jones NS. The surgeon's view of the anterior ethmoid artery. Clin Otolaryngol. 2006 Jun: 31(3):187-91. DOI: 10.1111/j.13652273.2006. 01191.x; PMID: 16759237.

2. Souza SA, Souza MM, Gregoria LC, Ajzen S. Anterior Ethmoidal Artery Evaluation on Coronal CT Scans. Braz J Otorhinolaryngol. 2009 Jan-Feb; 75(1):101-6. PMID: 19488568.

3. Jang DW, Lachanas VA, White LC, Kountakis SE. Supraorbital ethmoid cell: a consistent landmark for endoscopic identification of the anterior ethmoidal artery. Otolaryngol Head Neck Surg. 2014 Dec; 151(6): 1073-1077. DOI: 10.1177/0194599814551124; PMID: 25257902.

4. Bhatt NJ, Yardimci S. Supraorbital Ethmoidal Cell: Anatomical Prevalence and Surgical Significance. Otolaryngol Head Neck Surg. 2004 Aug; 131(2).

5. Zhang L, Han D, Ge W, Tao J, Wang X, Li Y, Zhou B. Computed tomographic and endocoscopic analysis of supraorbital ethmoidal cells. Otolaryngol Head Neck Surg. 2007 Oct; 137(4): 562-568. DOI: 10.1016/j.otohns.2007.06.737; PMID: 17903571.

6. Cho JH, Citardi MJ, Lee WT, Sautter NB, Lee HM, Yoon JH, et al. Comparison of frontal pneumatization patterns between Koreans and Caucasians. Otolaryngol Head Neck Surg. 2006 Nov; 135(5): 780-786. DOI: 10.1016/j.otohns.2006.05.750; PMID: 17071312.

7. Kubota K, Takeno S, Hirakawa K. Frontal recess anatomy in Japanese subjects and its effect on the development of frontal sinusitis: computed tomography analysis. J Otolaryngol Head Neck Surg. 2015 May 29; 44:21. DOI: 10.1186/s40463-015-0074-6; PMID: 26021826 PMCID: PMC4459068.

8. Comer BT, Kincaid NW, Smith NJ, Wallance JH, Kountakis SE. Frontal sinus septations predict the presence of supraorbital ethmoid cells. Laryngoscope. 2013 Sep; 123(9): 2090-2093. DOI: 10.1002/lary.23705; PMID: 23821470.

9. Ko YB, Kim MG, Gi Jung Y. The Anatomical Relationship between the Anterior Ethmoid Artery, Frontal Sinus, and Intervening Air Cells; Can the Artery Be Useful Landmark?. Korean Journal of Otorhinolaryngology-Head and Neck Surgery. 2014; 57(10): 687-691. DOI: : https://doi. org/10.3342/kjorl-hns.2014.57.10.687.

10. Comer BT, Kountakis SE. The Supraorbital Ethmoid Cell. In: Kountakis S, Senior B, DrafW (editors). The Frontal Sinus. Springer, Berlin, Heidelberg. 2016. pp. 315-323. 